\title{
Impact of the COVID-19 pandemic on the development of burnout syndrome in frontline physicians: prevalence and associated factors
}

\author{
Aline Roseane Queiroz de Paiva Faria ${ }^{1 *}$ (D), Hemílio Fernandes Campos Coelho (D),

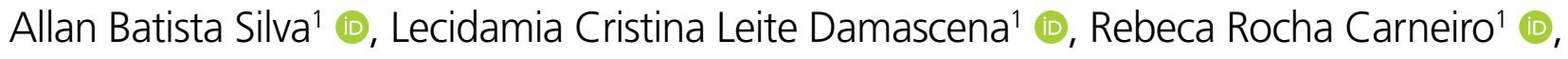 \\ Marina Travassos Lopes² (1), Kleyber Dantas Torres de Araújo ${ }^{1}$ (D), \\ Caliandra Maria Bezerra Luna Lima ${ }^{3}$
}

\begin{abstract}
SUMMARY
OBJECTIVE: To evaluate the prevalence of burnout syndrome (BS) in physicians working during the COVID-19 pandemic in Paraíba and to investigate the association between BS and the sociodemographic and labor variables of these professionals.

METHODS: This was a cross-sectional study including physicians who were active during the pandemic in Paraíba, whether they were on the front line (group 1) or not (group 2). Sociodemographic and labor variables were collected, and the Maslach Burnout InventoryHuman Services Survey (MBI-HSS) questionnaire was applied.

RESULTS: A total of 126 physicians were included, including 82 who were on the front line. Among the professionals with results compatible with BS, $85.5 \%$ were in group 1, compared with $14.5 \%$ in group 2, and this difference was statistically significant. At the $5 \%$ level, the variables associated with BS were age (24-33 years), not having children, working on the front line, working in the COVID19 ICU, being on duty, and having contracted COVID-19.

CONCLUSIONS: This case series found a positive association between the development of BS and medical action on the front line of the COVID-19 pandemic in Paraíba.

KEYWORDS: Coronavirus. Burnout. Health professional. Factor analysis statistical. Chi-square test.
\end{abstract}

\section{INTRODUCTION}

According to World Health Organization (WHO) data, as of May 2021, COVID-19 has affected more than 200 countries, resulting in approximately 159 million cases and approximately 3 million deaths ${ }^{1}$. In Brazil, this number has been increasing considerably, with more than 15 million cases and approximately 428,000 deaths from the disease reported as of May $2021^{2}$.

Infection with the new coronavirus, SARS-CoV-2, which causes a severe acute respiratory syndrome known as COVID-19, may be asymptomatic or can cause problems ranging from mild respiratory tract symptoms to sepsis and multiple organ

\footnotetext{
'Universidade Federal da Paraíba, Departamento de Estatística - João Pessoa (PB), Brazil. ${ }^{2}$ Universidade Federal da Paraíba, Departamento de Psicologia - João Pessoa (PB), Brazil.

${ }^{3}$ Universidade Federal da Paraíba, Departamento de Fisiologia e Patologia - João Pessoa (PB), Brazil.

*Corresponding author: alinerqpaiva@gmail.com

Conflicts of interest: the authors declare there is no conflicts of interest. Funding: none.

Received on May 13, 2021. Accepted on June 4, 2021.
} 
failure, which is life-threatening; thus, it has led to a significant increase in hospitalizations ${ }^{3}$.

The increase in the number of cases and their evolution has caused an overload of health systems, especially in Brazil. As a result of this workload, many health professionals may experience burnout, fatigue, and stress, among other risk factors for physical and mental illness ${ }^{3}$.

Burnout syndrome (BS) or burnout is a possible effect of chronic exposure to occupational stress and affects health professionals, particularly those working in hospitals ${ }^{4}$. It is believed that with the overload of health services, many professionals may have developed the disorder, with impacts on both the life of professionals and the care they provide.

The present study aimed to evaluate the prevalence of BS in physicians working during the COVID-19 pandemic in Paraíba and to verify its association with the sociodemographic and labor variables of these professionals.

\section{METHODS}

This was a cross-sectional study that included physicians of both sexes who worked during the COVID-19 pandemic in Paraíba, either on the front line (group 1) or off it (group 2). The physicians were recruited by e-mail and/or telephone in November 2020. The sample was obtained from the medical departments of reference hospitals for COVID-19 (group 1) and nonreference hospitals (group 2). Those who did not meet the inclusion criteria or did not adequately complete the data collection instrument were excluded.

The study was approved by the research ethics committee under no. 4,354,660 and followed the standards for research in humans.

A questionnaire was administered via Google Forms to obtain free and informed consent, collect sociodemographic and labor information, and administer the Maslach Burnout Inventory-Human Services Survey (MBI-HSS) questionnaire version validated for Portuguese 5 . The MBI-HSS consists of 22 items that reflect 3 dimensions: emotional exhaustion (EE; 9 items), depersonalization (DP; 5 items), and reduced personal achievement $(\mathrm{rPA} ; 8 \text { items })^{6}$.

The data were analyzed using $\mathrm{R}^{\circledR}$ software. To test the fit of the three-factor structure of the MBI-HSS, confirmatory factor analysis (CFA) was performed using the maximum likelihood method. The prevalence of BS was calculated, and the chi-square test was performed to investigate the association between the explanatory variables and the presence or absence of BS at a significance level of $5 \%$.

There is no consensus on adequate cutoff points for MBI-HSS results. The manual published by Maslach et al. ${ }^{6}$ advises that each dimension be analyzed separately to obtain the diagnosis from high EE and DP indices and low $\mathrm{rPA}^{6}$. The five-point Likert scale was used according to the adaptation validated by $\mathrm{Tamayo}^{7}$, applied in some studies in Brazil ${ }^{8,9}$. Individuals with mean response options equal to or higher than "sometimes" (a score of 3 on the Likert scale) for the EE and ED dimensions or scores of 3 or less for the rPA dimension were considered to have a high risk of BS.

\section{RESULTS}

A total of 126 physicians who were working during the pandemic were included, comprising 82 physicians who were on the front line (group 1) and 44 who were not (group 2). Females were prevalent in both the groups.

The mean age was 33.77 years in group 1 and 38.02 in group 2 . The majority $(54.9 \%)$ of the professionals in group 1 had COVID-19, compared with $4.5 \%$ in group 2. Descriptive statistics are presented in Table 1.

Through exploratory factor analysis (EFA), the fit of the data was observed, and $64.01 \%$ of the variance was explained. The adequacy of the original three-factor structure of the MBI-HSS was tested using CFA. The EE domain was composed of items $1,2,3,6,8,13,14,16$, and 20; the DP domain was composed of items $5,10,11,15$, and 22; and the rPA domain included items 4, 7, 9, 12, 17,18 19, and 21.

The CFA obtained the following results for the three-dimensional model: $\chi(206)=295.25 ; \mathrm{p}<0.001$; comparative fit index $(\mathrm{CFI})=0.965 ;$ Tucker-Lewis index $(\mathrm{TLI})=0.961$; and root mean square error of approximation (RMSEA) $=0.059$ with $95 \% \mathrm{CI}$ $0.043-0.073$, confirming the adequacy. The internal consistency estimated by Cronbach's alpha was substantial: 0.89 (EE), $0.66(\mathrm{DP})$, and $0.82(\mathrm{rPA})$.

The categorization of BS dimensions was performed using the cutoff points from the Maslach et al., manual ${ }^{6}$ : for EE: $\geq 27$ (high), 17-26 (moderate), and $\leq 16$ (low); for DP: $\geq 13$ (high), 7-12 (moderate), and $\leq 6$ (low); for rPA: $\leq 31$ (high), 38-32 (moderate), and $\geq 39$ (low). Table 2 shows the distribution according to these levels.

The results of the chi-square test are shown in Table 3. The statistically significant variables at the 5\% level were age between 24 and 33 years ( $\mathrm{p}=0.008)$, not having children $(\mathrm{p}=0.004)$, working on the front line $(\mathrm{p}<0.001)$, working in the COVID ICU, being on-duty $(\mathrm{p}=0.001)$, and having contracted COVID-19 $(\mathrm{p}=0.016)$. Among the professionals whose results were compatible with $\mathrm{BS}, 85.5 \%$ worked on the front line and $14.5 \%$ worked off the front the line, and this difference was statistically significant $(p<0.001)$. 
Table 1. Distribution of individuals according to sociodemographic and labor characteristics and COVID-19 infection history.

\begin{tabular}{|c|c|c|c|c|}
\hline \multirow{2}{*}{ Variable } & \multicolumn{2}{|c|}{ Front line } & \multicolumn{2}{|c|}{ Not front line } \\
\hline & $\mathrm{n}$ & $\%$ & $n$ & $\%$ \\
\hline \multicolumn{5}{|l|}{ Gender } \\
\hline Female & 45 & 54.9 & 36 & 81.8 \\
\hline Male & 37 & 45.1 & 8 & 18.2 \\
\hline \multicolumn{5}{|c|}{ Marital status } \\
\hline Married & 52 & 63.4 & 36 & 81.8 \\
\hline Other & 2 & 2.4 & 0 & 0 \\
\hline Separated & 5 & 6.1 & 4 & 9.1 \\
\hline Single75 & 23 & 28.0 & 4 & 9.1 \\
\hline \multicolumn{5}{|l|}{ Color } \\
\hline Yellow & 1 & 1.2 & 2 & 4.5 \\
\hline White & 55 & 67.1 & 30 & 68.2 \\
\hline Brown & 26 & 31.7 & 12 & 27.3 \\
\hline \multicolumn{5}{|c|}{ Comorbidities } \\
\hline Yes & 14 & 17.1 & 7 & 15.9 \\
\hline No & 68 & 82.9 & 37 & 84.1 \\
\hline \multicolumn{5}{|c|}{ Use of psychotropic drugs } \\
\hline Yes & 11 & 13.4 & 8 & 18.2 \\
\hline No & 71 & 86.6 & 36 & 81.8 \\
\hline \multicolumn{5}{|c|}{ Physical activity } \\
\hline Yes & 53 & 64.6 & 35 & 79.5 \\
\hline No & 29 & 35.4 & 9 & 20.5 \\
\hline \multicolumn{5}{|l|}{ Religious } \\
\hline Yes & 71 & 86.6 & 43 & 97.7 \\
\hline No & 11 & 13.4 & 1 & 2.3 \\
\hline \multicolumn{5}{|l|}{ Smoking } \\
\hline Yes & 3 & 3.7 & 1 & 2.3 \\
\hline No & 79 & 96.3 & 43 & 97.7 \\
\hline \multicolumn{5}{|c|}{ Alcoholic beverage consumption } \\
\hline Yes & 59 & 72.0 & 27 & 61.4 \\
\hline No & 23 & 28.0 & 17 & 38.6 \\
\hline \multicolumn{5}{|l|}{ Lives with } \\
\hline Friends & 1 & 1.2 & 0 & 0 \\
\hline Family & 64 & 78.0 & 42 & 95.5 \\
\hline Alone & 17 & 20.7 & 2 & 4.5 \\
\hline \multicolumn{5}{|l|}{ Has children } \\
\hline Yes & 40 & 48.8 & 33 & 75.0 \\
\hline No & 42 & 51.2 & 11 & 25.0 \\
\hline
\end{tabular}


Table 1. Continuation.

\begin{tabular}{|c|c|c|c|c|}
\hline \multirow{2}{*}{ Variable } & \multicolumn{2}{|c|}{ Front line } & \multicolumn{2}{|c|}{ Not front line } \\
\hline & $n$ & $\%$ & $n$ & $\%$ \\
\hline \multicolumn{5}{|l|}{ Type of service } \\
\hline COVID ward & 49 & 59.8 & 0 & 0 \\
\hline COVID ICU & 33 & 40.2 & 0 & 0 \\
\hline Other service (non-COVID) & 0 & 0 & 44 & 100 \\
\hline \multicolumn{5}{|l|}{ Position } \\
\hline Day worker & 9 & 11.0 & 26 & 59.1 \\
\hline On call & 73 & 89.0 & 18 & 40.9 \\
\hline \multicolumn{5}{|l|}{ Weekly workload } \\
\hline Less than $40 \mathrm{~h}$ & 29 & 35.4 & 17 & 38.6 \\
\hline Between 40 and $60 \mathrm{~h}$ & 25 & 30.5 & 25 & 56.8 \\
\hline Over $60 \mathrm{~h}$ & 28 & 34.1 & 2 & 4.5 \\
\hline \multicolumn{5}{|c|}{ Has more than one professional relationship } \\
\hline Yes & 74 & 90.2 & 35 & 79.5 \\
\hline No & 8 & 9.8 & 9 & 20.5 \\
\hline \multicolumn{5}{|c|}{ Considers their remuneration fair } \\
\hline Yes & 28 & 34.1 & 26 & 59.1 \\
\hline No & 54 & 65.9 & 18 & 40.9 \\
\hline \multicolumn{5}{|l|}{ Had COVID-19 } \\
\hline Yes & 45 & 54.9 & 2 & 4.5 \\
\hline No & 37 & 45.1 & 42 & 95.5 \\
\hline Total & 82 & 100.0 & 44 & 100.0 \\
\hline
\end{tabular}

Source: Research data. The values highlighted in bold are intended to draw the reader's attention to statistically significant variables.

Table 2. Distribution of professionals on the front line (group 1) and off the front line (group 2) for each dimension.

\begin{tabular}{l|c|c|c|c|c|c}
\multirow{2}{*}{\begin{tabular}{l}
\multirow{2}{*}{ Level } \\
\cline { 2 - 7 }
\end{tabular}} & \multicolumn{2}{|c}{ Emotional exhaustion } & \multicolumn{2}{c}{ Depersonalization } & \multicolumn{2}{c}{$\begin{array}{c}\text { Reduced professional } \\
\text { achievement }\end{array}$} \\
\cline { 2 - 8 } High & Front line & Off the front line & Front line & Off the front line & Front line & Off the front line \\
\hline Moderate & $41(50.0 \%)$ & $8(18.2 \%)$ & $31(37.8 \%)$ & $1(2.3 \%)$ & $53(64.6 \%)$ & $21(47.7 \%)$ \\
\hline Low & $32(39.0 \%)$ & $30(68.2 \%)$ & $45(54.9 \%)$ & $35(79.5 \%)$ & $27(32.9 \%)$ & $21(47.7 \%)$ \\
\hline
\end{tabular}

Source: Research data. The values highlighted in bold are intended to draw the reader's attention to statistically significant variables.

\section{DISCUSSION}

The present study explored the factors impacting the development of BS in physicians who worked at hospitals during the COVID-19 pandemic in Paraíba. The findings of this study showed that age between 24 and 33 years, not having children, working on the front line, working in the COVID ICU, being on call, and having contracted COVID-19 were statistically significant variables in relation to the outcome (the presence or absence of BS).

This study also showed that serving on the front line during the COVID-19 pandemic was the main factor associated with professional burnout in the population studied. 
Table 3. Results of the tests of association between the explanatory variables and the outcome (presence or absence of burnout syndrome).
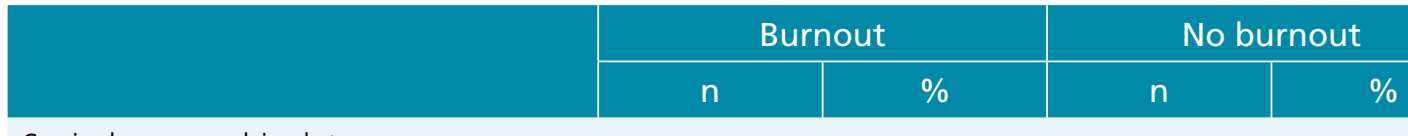

p-value

Sociodemographic data

\begin{tabular}{|c|c|c|c|c|c|}
\hline \multicolumn{5}{|l|}{ Age, years } & \multirow{4}{*}{0.008} \\
\hline $24-34$ & 32 & 58.2 & 22 & 31.0 & \\
\hline $34-44$ & 20 & 36.4 & 40 & 56.3 & \\
\hline $44-55$ & 3 & 5.5 & 9 & 12.7 & \\
\hline \multicolumn{6}{|l|}{ Gender } \\
\hline Female & 32 & 58.2 & 49 & 69.0 & \multirow{2}{*}{0.208} \\
\hline Male & 23 & 41.8 & 22 & 31.0 & \\
\hline \multicolumn{6}{|c|}{ Marital status } \\
\hline Married & 36 & 65.5 & 52 & 73.2 & \multirow{4}{*}{0.523} \\
\hline Single & 15 & 27.3 & 12 & 16.9 & \\
\hline Divorced & 13 & 23.6 & 6 & 8.5 & \\
\hline Other & 1 & 1.8 & 1 & 1.4 & \\
\hline \multicolumn{6}{|l|}{ Color } \\
\hline Yellow & 1 & 65.5 & 2 & 2.8 & \multirow{4}{*}{0.221} \\
\hline White & 33 & 27.3 & 52 & 73.2 & \\
\hline Brown & 21 & 23.6 & 17 & 23.9 & \\
\hline Black & 0 & 0.0 & 0 & 0.0 & \\
\hline \multicolumn{6}{|c|}{ Comorbidities } \\
\hline Yes & 8 & 14.5 & 13 & 18.3 & \multirow{2}{*}{0.574} \\
\hline No & 47 & 85.5 & 58 & 81.7 & \\
\hline \multicolumn{6}{|c|}{ Use of psychotropic drugs } \\
\hline Yes & 11 & 20.0 & 8 & 11.3 & \multirow{2}{*}{0.174} \\
\hline No & 44 & 80.0 & 63 & 88.7 & \\
\hline \multicolumn{6}{|c|}{ Physical activity } \\
\hline Yes & 37 & 67.3 & 51 & 71.8 & \multirow{2}{*}{0.580} \\
\hline No & 18 & 32.7 & 20 & 28.2 & \\
\hline \multicolumn{6}{|l|}{ Religious } \\
\hline Yes & 47 & 85.5 & 67 & 94.4 & \multirow{2}{*}{0.091} \\
\hline No & 8 & 14.5 & 4 & 5.6 & \\
\hline \multicolumn{6}{|l|}{ Smoking } \\
\hline Yes & 0 & 0.0 & 4 & 5.6 & \multirow{2}{*}{0.074} \\
\hline No & 55 & 100.0 & 67 & 94.4 & \\
\hline \multicolumn{6}{|c|}{ Alcohol consumption } \\
\hline Yes & 38 & 69.1 & 48 & 67.6 & \multirow{2}{*}{0.859} \\
\hline No & 17 & 30.9 & 23 & 32.4 & \\
\hline
\end{tabular}


Table 3. Continuation.

\begin{tabular}{|c|c|c|c|c|c|}
\hline & \multicolumn{2}{|c|}{ Burnout } & \multicolumn{2}{|c|}{ No burnout } & \multirow{2}{*}{ p-value } \\
\hline & $n$ & $\%$ & $n$ & $\%$ & \\
\hline \multicolumn{6}{|l|}{ Lives with } \\
\hline Friends & 1 & 1.8 & 0 & 0.0 & \multirow{3}{*}{0.195} \\
\hline Family & 43 & 78.2 & 63 & 88.7 & \\
\hline Alone & 11 & 20.0 & 8 & 11.3 & \\
\hline \multicolumn{6}{|l|}{ Has children } \\
\hline Yes & 24 & 43.6 & 49 & 69.0 & \multirow{2}{*}{0.004} \\
\hline No & 31 & 56.4 & 22 & 31.0 & \\
\hline \multicolumn{6}{|l|}{ Hours of sleep } \\
\hline Up to 6 & 37 & 67.3 & 37 & 52.1 & \multirow{2}{*}{0.086} \\
\hline More than 6 & 18 & 32.7 & 34 & 47.9 & \\
\hline \multicolumn{6}{|l|}{ Labor data } \\
\hline \multicolumn{6}{|c|}{ Front line professional } \\
\hline Yes & 47 & 85.5 & 35 & 49.3 & \multirow{2}{*}{$<0.001$} \\
\hline No & 8 & 14.5 & 36 & 50.7 & \\
\hline \multicolumn{6}{|l|}{ Type of service } \\
\hline COVID ICU & 22 & 40.0 & 11 & 15.5 & \multirow{3}{*}{$<0.001$} \\
\hline COVID ward & 25 & 45.5 & 24 & 33.8 & \\
\hline Other & 8 & 14.5 & 36 & 50.7 & \\
\hline \multicolumn{6}{|l|}{ Position } \\
\hline On call & 48 & 87.3 & 43 & 60.6 & \multirow{2}{*}{0.001} \\
\hline Day worker & 7 & 12.7 & 28 & 39.4 & \\
\hline \multicolumn{6}{|l|}{ Workload } \\
\hline Up to $40 \mathrm{~h}$ & 15 & 27.3 & 31 & 43.7 & \multirow{3}{*}{0.149} \\
\hline $40-60 h$ & 24 & 43.6 & 26 & 36.6 & \\
\hline More than $60 \mathrm{~h}$ & 16 & 29.1 & 14 & 19.7 & \\
\hline \multicolumn{6}{|c|}{ More than one professional relationship } \\
\hline Yes & 48 & 87.3 & 61 & 85.9 & \multirow{2}{*}{0.825} \\
\hline No & 7 & 12.7 & 10 & 14.1 & \\
\hline \multicolumn{6}{|c|}{ Satisfactory remuneration } \\
\hline Yes & 20 & 36.4 & 34 & $47.9 \%$ & \multirow{2}{*}{0.195} \\
\hline No & 35 & 63.6 & 37 & $52.1 \%$ & \\
\hline \multicolumn{6}{|l|}{ Had COVID-19 } \\
\hline Yes & 27 & 49.1 & 20 & 28.2 & \multirow{2}{*}{0.016} \\
\hline No & 28 & 50.9 & 51 & 71.8 & \\
\hline
\end{tabular}

Source: Research data. The values highlighted in bold are intended to draw the reader's attention to statistically significant variables. 
Among the professionals with results compatible with BS, $85.5 \%$ worked on the front line. Similar findings were observed in the studies by Kannampallil et al. ${ }^{10}$, Giusti et al. ${ }^{11}$, and Demartini et al. ${ }^{12}$; however, the findings differed from those reported by Wu et al. ${ }^{13}$, Dimitriu et al. ${ }^{14}$, and Dinibutum ${ }^{15}$, who found a higher prevalence of $\mathrm{BS}$ in professionals working off the front line than among those who dealt directly with the disease $\mathrm{e}^{13-15}$.

The highly contagious nature of COVID-19 coupled with the increased workload due to the overload of health services exposes these professionals to the risk of contracting the disease and spreading it to their families, which causes increased levels of stress and anxiety and, consequently, professional exhaustion ${ }^{10-12}$.

These findings should be considered because of their potential impact on clinical practice. The development of BS in health professionals, especially those in the medical field, can have serious consequences since it is associated with increased rates of medical error and decreased productivity, which compromises the quality of care for critically ill individuals ${ }^{16}$.

Studies conducted prior to the pandemic showed a prevalence of BS that was greater than $40 \%$ and was higher in professionals working in emergency departments and ICUs ${ }^{17}$. COVID-19 introduced additional stress factors, such as fear of contracting the infection, fear of spreading the infection to family members, and social isolation ${ }^{18}$; these additional factors caused symptoms of stress and depression that impacted the physical and mental health of health care professionals ${ }^{19}$.

The MBI is the most commonly used instrument for measuring occupational burnout and is considered the gold standard ${ }^{6}$. There is a lack of data in the literature applying this tool to professionals working directly with COVID-19. One of the first studies included 220 physicians and found a 25\% increase in EE and DP and an approximately 50\% increase in $\mathrm{rPA}^{13}$. In this case series, among physicians working on the front line, these rates were $50 \%$ (EE), 23\% (DP), and $64 \%(\mathrm{rPA})$, with the latter two being similar to the findings of the cited study.

Comparatively, a study by Giusti et al. ${ }^{11}$ that applied the MBIHSS to 330 health professionals showed that $66.7 \%$ had moderate to high levels of EE and rPA and 25\% had moderate to high levels of $\mathrm{DP}^{11}$, similar to the indices found in the present study.

The results of the chi-square test showed that gender was not a significant factor, corroborating the findings of the literature ${ }^{20,21}$; however, the results of the present study differ from those of Kannampallil et al. ${ }^{10}$ and a recent study conducted in Brazil that reported a higher prevalence of BS in females ${ }^{22}$.
Age was divided into three groups, and age between 24 and 34 years was found to be a significant factor, indicating a higher prevalence of BS in younger professionals $(\mathrm{p}=0.008)$. This finding that disagrees with that of Gunasingam et al. ${ }^{23}$, in which there was no association between burnout and age. However, it was consistent with other studies in which younger participants had a higher prevalence of $\mathrm{BS}^{22,24}$.

Working in the ICU was associated with a higher prevalence of burnout ( $\mathrm{p}=0.001$ ), similar to the findings of a case series that included 1001 European intensivists ${ }^{25}$ in which BS was present in 52\%. Finally, having contracted COVID19 was associated with a higher prevalence of BS ( $p=0.016)$, with statistical significance for all constructs. Similar findings were observed in a study of 330 health professionals in northern Italy ${ }^{11}$.

\section{CONCLUSIONS}

The occurrence of BS among health professionals (particularly those in the medical field) working on the front line of the COVID-19 pandemic is undeniable and is an important factor to consider not only because of its impact on the mental health of these professionals but also because of its potential to compromise patient care.

In this case series, a positive association was found between the development of BS and action on the front line of the pandemic among physicians in Paraíba. In addition, the following variables were identified as significant factors: age between 24 and 33 years, not having children, working on the front line, working in the COVID ICU, being on call, and having contracted COVID-19.

These results highlight the importance of the early diagnosis and management of BS in doctors working on the front line during the pandemic to establish concrete measures that can increase support for the physical and mental health of these professionals.

\section{AUTHORS" CONTRIBUTIONS}

ARQPF: Conceptualization, Data curation, Investigation, Writing - original draft, Writing - review \& editing. HFCC: Formal analysis, Project administration, Supervision. ABS: Conceptualization, Writing - original draft. LCLD: Writing - review \& editing. RRC: Writing - review \& editing. MTL: Formal analysis, Methodology. KDTA: Writing review \& editing. CMBLL: Supervision, Project administration, Visualization. 


\section{REFERENCES}

1. World Health Organization. Coronavirus (COVID-19) dashboard [Internet]. World Health Organization; 2021 [cited on 2021 May 12]. Available from: https://covid19.who.int/

2. Ministério da Saúde. Coronavírus Brasil. Painel coronavírus [Internet]. Ministério da Saúde; 2021 [cited on 2021 May 12]. Available from: https://covid.saude.gov.br/

3. Lourenção LG. A Covid-19 e os desafios para o Sistema e os profissionais de saúde. Enferm Foco (Brasília). 2020;11(1):2-3.

4. Perniciotti $P$, Serrano Júnior $C V$, Guarita RV, Morales RJ, Romano BW. Síndrome de Burnout nos profissionais de saúde: atualização sobre definições, fatores de risco e estratégias de prevenção. Rev SBPH. 2020;23(1):35-52.

5. Lautert L. O desgaste profissional: estudo empírico com enfermeiras que trabalham em hospitais. Rev Gaúcha Enferm. 1997;18(2):133-44

6. Maslach C, Jackson SE, Leiter M. The Maslach Burnout Inventory Manual. $3^{\text {rd }}$ ed. Palo Alto: Consulting Psychologists Press; 1996.

7. Tamayo MR. Relação entre a síndrome de Burnout e os valores organizacionais no pessoal de enfermagem de dois hospitais públicos [dissertação]. Brasília: Instituto de Psicologia, Universidade de Brasília; 1997.

8. Lorenz VR, Sabino MO, Corrêa Filho HR. Esgotamento profissional, qualidade e intenções entre enfermeiros de saúde da família. Rev Bras Enferm. 2018;71(suppl 5):2429-305. https://doi.org/10.1590/0034-7167-2016-0510

9. Rocha Junior L, Cortes MCJW, Dias EC, Fernandes FM, Gontijo ED. Burnout and job satisfaction among emergency and intensive care providers in a public hospital. Rev Bras Med do Trab. 2019;17(3):300-12. https://doi.org/10.5327/ Z1679443520190404

10. Kannampallil TG, Goss CW, Evanoff BA, Strickland JR, McAlister RP, Duncan J. Exposure to COVID-19 patients increases physician trainee stress and burnout. PLoS One. 2020;15(8):e0237301. https://doi.org/10.1371/journal.pone.0237301

11. Giusti EM, Pedroli E, D'Aniello GE, Badiale CS, Pietrabissa G, Manna C, et al. The psychological impact of the COVID-19 outbreak on health professionals: a cross-sectional study. Front Psychol. 2020;11:1684. https://doi.org/10.3389/ fpsyg.2020.01684

12. Demartini B, Nisticò $\vee$, $D^{\prime}$ Agostino A, Priori A, Gambini O. Early psychiatric impact of COVID-19 pandemic on the general population and healthcare workers in Italy: a preliminary study. Front Psychiatry. 2020;11:561345. https://doi.org/10.3389/ fpsyt.2020.561345

13. Wu Y, Wang J, Luo $C$, Hu S, Lin X, Anderson AE, et al. A comparison of burnout frequency among oncology physicians and nurses working on the frontline and usual wards during the COVID-19 epidemic in Wuhan, China. J Pain Symptom Manage. 2020;60(1):e60-e65. https://doi.org/10.1016/j. jpainsymman.2020.04.008
14. Dimitriu MCT, Pantea-Stoian A, Smaranda AC, Nica AA, Carap $A C$, Constantin VD, et al. Burnout syndrome in Romanian medical residents in time of the COVID-19 pandemic. Med Hypotheses. 2020;144:109972. https://doi.org/10.1016/j. mehy.2020.109972

15. Dinibutun SR. Factors associated with burnout among physicians: an evaluation during a period of COVID-19 pandemic. Healthc Leadersh. 2020;12:85-94. https://doi.org/10.2147/ JHL.S270440

16. Bradley $\mathrm{M}$, Chahar P. Burnout of healthcare providers during COVID-19. Cleve Clin J Med. 2020. https://doi.org/10.3949/ ccjm.87a.ccc051

17. West CP, Dyrbye LN, Shanafelt TD. Physician burnout: contributors, consequences and solutions. J Intern Med. 2018;283(6):516-29. https://doi.org/10.1111/joim.12752

18. SCCM COVID-19 rapid-cycle survey 2 report. Society of Critical Care Medicine; 2020. Available from: https://sccm. org/getattachment/Blog/May-2020/SCCM-COVID-19-RapidCycle-Survey-2-Report/COVID19-Clinicians-Are-Stressed-RapidAssessment.pdf?lang=en-US

19. Stehman CR, Testo Z, Gershaw RS, Kellogg AR. Burnout, drop out, suicide: physician loss in emergency medicine, part I. West J Emerg Med. 2019;20(3):485-94. https://doi.org/10.5811/ westjem.2019.4.40970

20. Pu J, Zhou X, Zhu D, Zhong X, Yang L, Wang H, et al. Gender differences in psychological morbidity, burnout, job stress and job satisfaction among Chinese neurologists: a national cross-sectional study. Psychol Health Med. 2017;22(6):680-92. https://doi.org/10.1080/13548506.2016.1211717

21. Wu H, Liu L, Wang Y, Gao F, Zhao X, Wang L. Factors associated with burnout among Chinese hospital doctors: a cross-sectional study. BMC Public Health. 2013;13:786. https://doi.org/10.1186/1471-2458-13-786

22. Civantos AM, Bertelli A, Gonçalves A, Getzen E, Chang C, Long $Q$, et al. Mental health among head and neck surgeons in Brazil during the COVID-19 pandemic: a national study. Am J Otolaryngol. 2020;41(6):102694. https://doi.org/10.1016/j. amjoto.2020.102694

23. Gunasingam N, Burns K, Edwards J, Dinh M, Walton M. Reducing stress and burnout in junior doctors: the impact of debriefing sessions. Postgrad Med J. 2015;91(1074):182-7. https://doi.org/10.1136/postgradmedj-2014-132847

24. Scheurer D, McKean S, Miller J, Wetterneck T. U.S. physician satisfaction: a systematic review. J Hosp Med. 2009;4(9):560-8. https://doi.org/10.1002/jhm.496

25. Azoulay E, De Waele J, Ferrer R, Staudinger T, Borkowska M, Povoa $P$, et al. Symptoms of burnout in intensive care unit specialists facing the COVID-19 outbreak. Ann Intensive Care. 2020;10(1):110. https://doi.org/10.1186/s13613-020-00722-3 